\title{
$\left.\mathbf{C}^{-}\right\rceil$CONGRESO
INTERNACIONAL \\ SOBRE \\ LF_O FOTOGRAFÍA
}

Congreso Internacional sobre Fotografía

UPV, 5 y 6 octubre 2017

Doi: http://dx.doi.org/10.4995/CIFo17.2017.6775

ISBN: 978-84-9048-604-7

\section{Humberto Rivas y la fotografía española de los $\mathbf{7 0}$.}

Ana Rosa Gómez Arroyo. Universidad Politécnica de Valencia.

\section{Resumen:}

La fotografía expresa la realidad político social del país. En 1978 en España se instaura la democracia, y con ello el nacimiento de un nuevo fotoperiodismo español. La fotografía es introducida en el ámbito universitario, y junto la apertura de galerías y centros fotográficos contribuirán a dinamizar el sector convirtiéndose en núcleo de información y debate. Estos factores, junto a la situación político social de Argentina empujan a Humberto Rivas a instalarse en España.

Partiendo de estudios y publicaciones especializadas nacidas en la década, se profundizará en la investigación mediante la información recogida en entrevistas, documentos, y el acceso a los fondos fotográficos del artista; aportando un enriquecimiento tanto formal como sensorial a la transmisión de la lectura de sus imágenes.

La llegada del artista a Barcelona supuso una renovación del panorama fotográfico español de aquel momento en el que surgían nuevos planteamientos fotográficos de acuerdo a las corrientes internacionales, agrupando e influyendo en numerosos fotógrafos. Esta investigación profundiza en la particularidad del debate fotográfico de los 70, analizando y por tanto destacando la aportación de la obra de Humberto Rivas a la historia de la fotografia española.

\section{Palabras clave:}

Huberto Rivas; Fotografia; Historia; Cultura; Retrato; Paisaje; Rostro; Máscara 


\begin{abstract}
Photography expresses the social political reality of the country. In 1978, the Spainish democracy is established, and with it the birth of a new Spanish photojournalism. Photography is introduced in the university, opening painting galleries and photographic centers which will contribute to energize the sector becoming it in a nucleus of information and discussion. These factors and also the social political situation in Argentina, push Humberto Rivas to settle down in Spain.

Starting from the studies and specialized publications born in the decade, the research will be developed through the information collected in interviews, documents and access to the photographic funds of the artist; which ones contributing with a formal and sensorial enrichment to the transmission of the reading their images.

The arrival of the artist in Barcelona meant a renovation of the Spanish photographic panorama of that moment in which new photographic approaches appeared according to the international tendency, with numerous photographers grouping and influencing. This research studies into the particularity of the photographic debate of the 70, analyzing and therefore highlighting the contribution of Humberto Rivas' work to the history of Spanish photography.
\end{abstract}

\title{
Keywords:
}

Humberto Rivas; Photography; History; Culture; Portrait; Landscape; Face; Mask.

Como cualquier otro lenguaje artístico, una de las facetas de la fotografía es reflejar el momento político social por el que atraviesa la sociedad. Nos adentraremos en el análisis de los años 70 , centramos en la cultura catalana al ser el entorno en que se desenvolvió principalmente Humberto Rivas (Fig. 1). Nos situaremos en el contexto político social que tanto España como Argentina vivían en aquel momento comprendiendo los motivos que le empujan al artista a instalarse en nuestro país, para posteriormente conocer la cultura fotográfica y la educación en esta década, fundamental para la reivindicación de la fotografía como medio de expresión. Todo esto analizando la incorporación de Humberto Rivas a la fotografía catalana y española, y su interacción con los fotógrafos, las instituciones y la cultura. Destacando la importante contribución de la fotografía de Humberto 
Rivas a la renovación del panorama fotográfico español, analizando las características de su obra en estos años. Para ello, se partirá de estudios de historiadores de la fotografía y publicaciones especializadas nacidas en la década, profundizando en la investigación mediante la información recogida en entrevistas, documentos, y el acceso a los fondos fotográficos del artista; aportando un enriquecimiento tanto formal como sensorial a la transmisión de la lectura de sus imágenes.

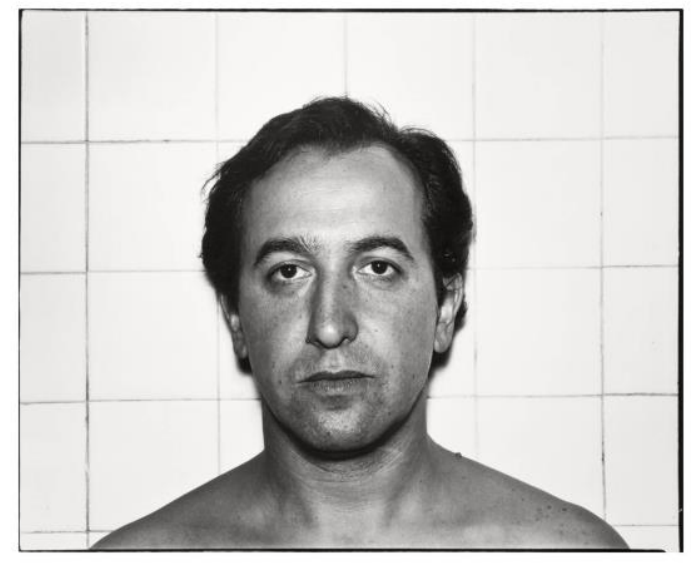

(Fig. 1) Autorretrato, 1978. Archivo Humberto Humberto Rivas.

Los objetivos planteados son estudiar el Contexto cultural y político-social de la España de los 70. Analizar la incorporación de Humberto Rivas a la fotografía catalana y española, y su interacción con los fotógrafos, las instituciones y la cultura. Investigar el trabajo fotográfico del artista realizado en esta época, e identificar características formales representativas de sus imágenes de este periodo. Analizar brevemente su evolución tomando como punto de partida los años 70. Destacar la importancia de Humberto Rivas en la historia del retrato fotográfico español. Ubicarlo e indagar en la repercusión de su obra en artistas influenciados por él.

Los años 70 fue una década esencial para el desarrollo de la fotografía española. Se abrieron salas de exposición y galerías, se crearon nuevas revistas como Nueva Lente en 1971, escuelas, academias, y se cimentaron las bases del desarrollo del mercado fotográfico. - En 1970 se inaguró en Madrid la Galería Redor, en 1972 aparecía el primer anuario Spafoto, y un año después lo hacían los anuarios Coteflash y Everfoto. En 1974 se publicaba el primer número de la revista Flash-Foto, y se inauguraba en Madrid el polivalente Photocentro - (Plubio, 1997).

En España la muerte del general franco el 20 de noviembre de 1975 dio paso a una etapa indecisa en que la agitación sindical contribuyó en buena medida a forzar la transición a la democracia (Fontana, 2011). En 1978 se vivía el inicio de una reforma política tras la muerte de Franco, una época de transición que acabaría con la instauración de la democracia; y con ello el nacimiento de un nuevo fotoperiodismo español, se crearon nuevas empresas periodísticas y otras cabeceras históricas cerraron. La fotografía es introducida en el ámbito universitario e inicia sus actividades en Barcelona Institut d'Estudis Fotográfics de Cataluya (1972) y Madrid el 
CEI (Centro de Enseñanzas de la Imagen). Al mismo tiempo, Argentina a pesar de una antesala de 11 años de crecimiento económico no pudo ser ajena a la crisis económica mundial de 1973, una decadencia social y política también, que en 1975 situaba la economía al borde del colapso con el desencadenamiento de un golpe de estado el 24 de marzo de 1976. A pesar de esto, la cultura seguía siendo fuerte; no obstante, estos factores, unidos a los personales como el consecuente cierre del Instituto di Tella dónde trabajaba como fotógrafo, empujan a Humberto Rivas a instalarse en España. La llegada del artista a Barcelona el 24 de marzo de 1976 supuso una renovación del panorama fotográfico español de aquel momento, numerosos fotógrafos se agruparon en torno a él. Cuando llegó a Barcelona a la única persona que conocía era a Juan Carlos Pérez Sánchez, conocido como América Sánchez y a través de él entro a trabajar en el taller de Xavier Corberó, un escultor Barcelonés al que Humberto Rivas le hacía las fotografías, trabajo para él en el Centro de Actividades e Investigaciones Artísticas en Barcelona durante los años 1976 y 77.

En la década de los 70 fue muy importante la labor de Albert Ripoll Guspi, conocido como Albert Guspi, por ser el dinamizador de la cultura fotográfica. El 4 de octubre de 1978 se inauguró el Centre Internacional de Fotografía Barcelona (CIFB) El centro marcó una inflexión en la cultura fotográfica española, puesto que se trataba de una institución singular y pionera en su género, un espacio que incluía centro de exposición y formación (Zelich y Ribalta, 2012). La idea que Guspi traslado al Cifb fue la labor del fotógrafo como un proceso complejo y reflexivo que no se limita a la toma de imágenes, sino que consiste en construir, a través de la edición de tales imágenes, un punto de vista personal o un ensayo fotográfico que se difunde después mediante la publicación, el audiovisual y la exposición (Plasencia y Faus, 2011).

Albert Guspi junto a Sandra Solsona fundan la galería Spectrum en Barcelona, en 1973. La galería Spectrum se inició con una programación que combinaba la presencia de fotógrafos internacionales contemporáneos de gran resonancia en su momento, y de autores españoles. Gracias a ellos la galería estableció su influencia en la escena local, y demostró su capacidad para aglutinar y promover a una nueva generación de fotógrafos creativos. En octubre de 1976 paso a llamarse Spectrum Canon al recibir apoyo financiero de la marca por el contrato que firmó con Focica S.A.

En 1975 nace el Grup Taller d'Art Fotogràfic, una escuela de fotografía creativa coordinada por Lara Castells. Fue un espacio de referencia para fotógrafos emergentes en la segunda mitad de los setenta, formada entre otros por Humberto Rivas, Mariano Zunzunaga, Manolo Laguillo, Pere Formiguera, Manel Esclusa o Koldo Chamorro. El profesorado estaba constituido por alguno de los artistas de la galería. El Taller Grup impulsó iniciativas como la revista Imatge en la que colaboraban Joan Fontcuberta y Mariano Zunzunaga; y organizó el Taller Mediterráneo de Fotografía en Cadaqués, inspirado en los Encuentros Internacionales de Fotografía de Arlés, era una semana de realización de Talleres a cargo de artistas nacionales e internacionales, además de exposiciones. Tras el convenio con Canon en 1977, el Grup Taller pasó a ser Taller Fotográfico Spectrum Canon. A través del boletín Spectrum News se ofrecían becas para los estudios de fotografía, así como cursillos infantiles gratuitos durante los fines de semana. También se difundían los seminarios que se organizaban. Así, por ejemplo, en el boletín de septiembre de 1977 se anunciaba un seminario sobre retrato a cargo de Humberto 
Rivas (Zelich y Ribalta, 2012), a través de estas actividades se refleja la idea que Guspi traslado al CIFB, la del proceso complejo y reflexivo del fotógrafo mencionado anteriormente.

El CIFB jugó un importante papel en la fotografía y el mundo de la imagen, se fundamentaba en una concepción de la fotografía como un arte popular y de la comunicación masiva, cuya función social no se limitaba al campo del arte autónomo. Se ofrecía como una institución para la formación de fotógrafos profesionales y creativos, así como para la promoción de la cultura fotográfica y el debate público en el sentido más amplio, al margen de los límites profesionales de la producción audiovisual. Desde el CIFB se pretendía crear una plataforma para dar a conocer a fotógrafos -que entendían el reportaje como un trabajo de investigación riguroso y prolongado en el tiempo, lejos de la mera fotografía de actualidad. Ofrecía tanto programas de formación como talleres puntuales y buscaba vías diversas de inserción en el barrio y en la vida social de la ciudad. Organizaba exposiciones, talleres, conferencias y debates, programas de cine y proyecciones, y publicaba la revista Imatge. También hacía hincapié en facilitar medios para la producción fotográfica y audiovisual y su inserción en el debate público a través de proyectos sobre la ciudad.- La docencia en el CIFB era la misma que la del Group Taller, se inclinaba más hacia la fotografía creativa.

En este momento crecían otras alternativas en la ciudad, nacieron nuevas galerías como por ejemplo Fotomanía en 1977 con Cristina Zelich. En 1981 la enseñanza de la fotografía llega a la universidad a la Facultad de Bellas Artes, la oferta educativa se había multiplicado. Las Jornadas Catalanas de Fotografía en 1980 marcaron el destino de la fotografía creativa durante casi dos décadas, su eje vertebrador era la Primavera Fotográfica iniciada en 1982.

Humberto Rivas, como se ha mencionado anteriormente, fue profesor en el Grup Taller D'Art Fotografic en 1976, a través de estos talleres empezó a relacionarse con otros fotógrafos (Fig. 2). La primera exposición que Humberto Rivas realizó en España fue en la galería Spectrum Canon en 1977 (Fig.3) con los personajes de la cultura catalana, en ese mismo año volvió a participar en la galería en una exposición colectiva "Fotógrafos Argentinos" con Carlos Boch entre otros. También en 1977 expone en la Galería Tau de Sant Celoni, era un colectivo de fotógrafos que decidieron abrir un espacio fotográfico donde hacer exposiciones y otras actividades y tenían muy buena relación con la Galería Spectrum (no era una sucursal), con Albert Guspi, muchos proyectos que se exponían en Spectrum después pasaban a la Galería Tau. En 1978 expone con 35 fotógrafos en la Galería Prouset (Fig.4). En 1979 expone en Fotomanía, momento en el que comienza su amistad con Cristina Zelich, en 1981 vuelve a exponer en la Galería en una exposición colectiva de desnudo en la que participa junto a Toni Catany, Manolo Laguillo, Eduard Olivella, y Joan Fontcuberta. Y en 1982 partició en la Primavera Fotográfica en una exposición de Fotografía contemporánea en Cataluña. 


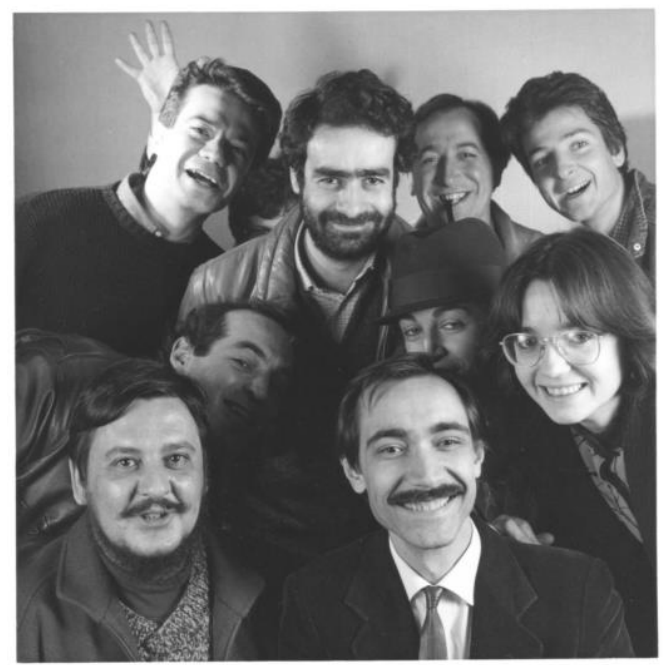

(Fig. 2) Imagen de Cristina Zelich
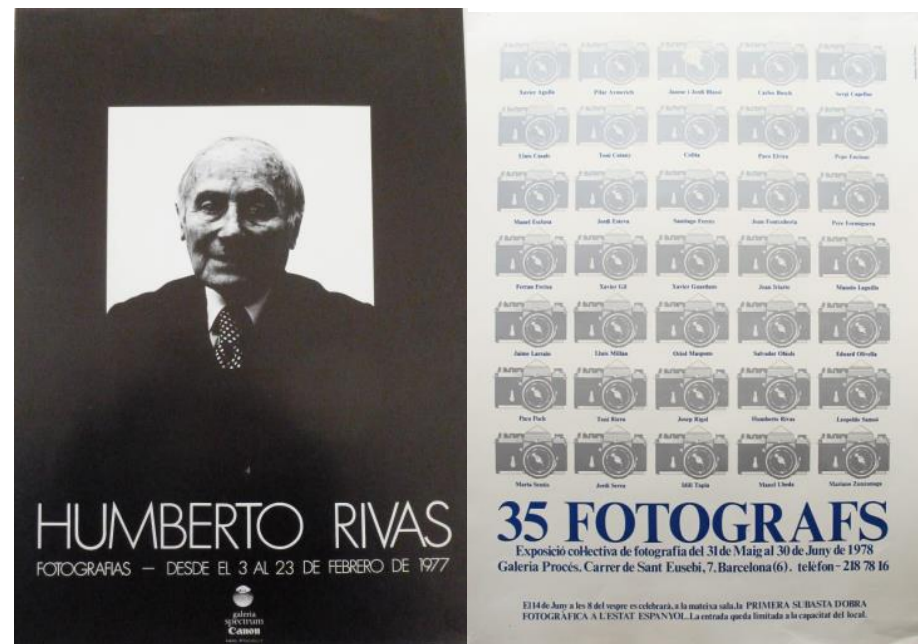

(Fig. 3 y 4) Carteles exposiciones.

La interacción entre estos fotógrafos traspaso las fronteras, en 1980 la Galería Eude organiza una exposición colectiva bajo el título Homenaje a Man Ray. Fue una exposición sobre fotografía española itinerante en Gran Bretaña por iniciativa de la Night Gallery de Londres, tuvo lugar en la Photographer's Gallery (Londres) del 15/11/1980 - 08/12/1980, Night Gallery (Londres), la Sala del Instituto de España en Londres, la Photographic Gallery (Cardiff), Open Eye Gallery (Liverpool), y el Departamento de Fotografía del Politécnico de Manchester. En las exposiciones participan Jaume i Jordi Blassi, Manel Exclusa, Toni Catany, Joan Fontcuberta, Manolo Laguillo, Ferrán Freixa y Humberto Rivas (Fig. 5). El British Journal of Photography dedicó tres números distintos a varios portfolios de algunos de los autores participantes. Humberto Rivas participa con una fotografía del Zoo de Londres realizada en 1979. 


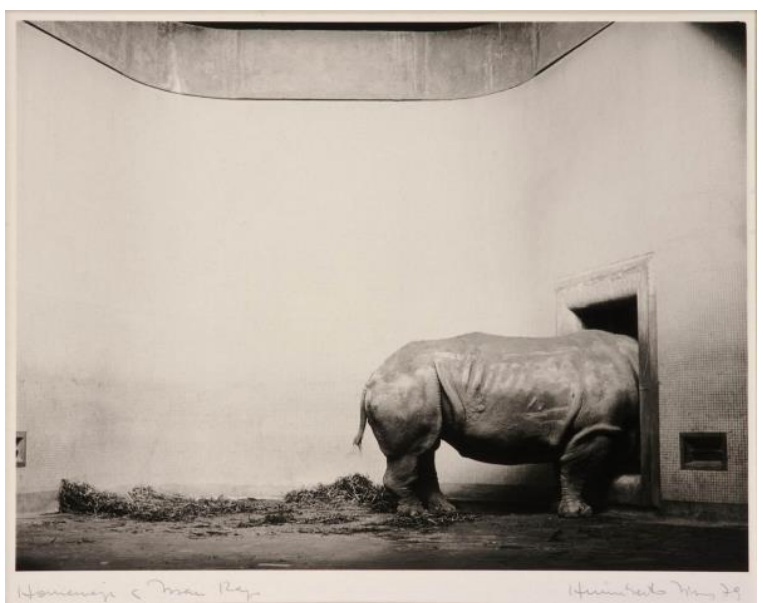

(Fig. 5) Homenaje a Man Ray, Humberto Rivas

En Barcelona se crearon grupos para intentar promocionarse, ayudarse y aprovechar la iniciativa de los demás, el más conocido fue el Grupo Alabern, este grupo reivindicaba la "fotografía de autor" como expresión artística. El artísta nunca participó en ellos, pero fue muy activo en la organización de las Jornadas Catalanas.

Humberto Rivas hizo puente entre los fotógrafos y los artistas plásticos, sus orígenes en el arte fueron pictóricos. Para el artista un fotógrafo era una persona que conocía muy bien la técnica, pero sus imágenes no tenían ese contenido que traspasa el umbral del soporte fotográfico. Para él la fotografía artística se hace pensando y utilizando el medio como vehículo de expresión, eso es para él el artista. Humberto unió al fotógrafo que utilizaba la luz como medio de expresión en el arte.

Al mismo tiempo, a finales de los 70, aparecen otros fotógrafos que lo que les interesa es esa documentación de la ciudad siempre desde un punto de vista muy subjetivo, por ejemplo, Joan Fontcuberta, Manel Úbeda y Luis Casals. En el trabajo de Humberto había un rigor, muy preciso, él se enfrentaba a la realidad desde un punto de vista subjetivo, pero en el que la composición y el control de la iluminación era muy importante. El no hacia una fotografía fantástica como otros fotógrafos, (aunque no todos, Ferrán Freixa por ejemplo hacía documentalismo poético), era el contrapunto a esa fotografía fantástica o surrealista que se hacía en aquel momento (Fig. 6), Humberto Rivas era defensor de la fotografía directa, pero con una clara implicación del propio autor.

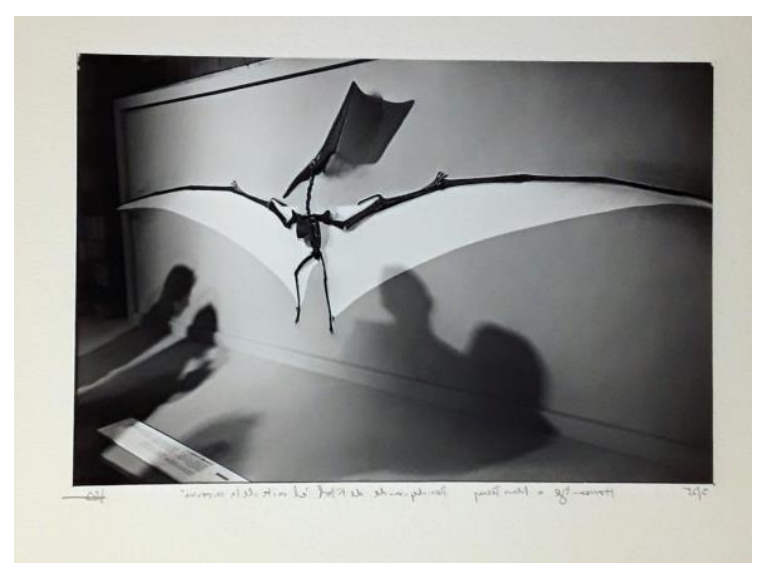

(Fig. 6) Homenaje a Man Ray, Joan Fontcuberta 
El artista trata los mismos temas toda su trayectoria. Cambiará los formatos, de medio formato a la cámara de placas, la panorámica en el paisaje, pero los temas son los mismos.

El origen de la producción fotográfica de Humberto Rivas se encuentra en el cine y su admiración por Ingmar Bergman. Su fotografía está empapada de referentes pictóricos tales como Francis bacon, Durero y Rembrant; fotográficos, Richard Avedon, Diane Arbus y August Sander; cinematográficos, Ingmar Bergman y Sven Nykvist ; y literarios, Fernando Pessoa y Marcel Proust.

Sus imágenes reflejan su más íntima esencia, son su autorretrato, el resultado de una mirada directa y sutil, con la que empapa ha retratado y espectador de su personalidad (Fig. 7). Son imágenes sobrias y sencillas dónde la memoria y el paso del tiempo está presente. "Aunque es fiel a la representación de la realidad lo invisible es protagonista, es el sentido visual de la imagen" (Schnaith, 2011:11). Los trazos del tiempo son perceptibles en sus retratos, fotografías de esquinas, de lugares en abandono, y de ángulos interiores. Construye la imagen a partir de bases geométricas existentes en las formas visibles y las refuerza con luces sugerentes, que contribuyen a la creación de ese clima concebido previamente y que irá perfilando su forma de expresión y su propio retrato.

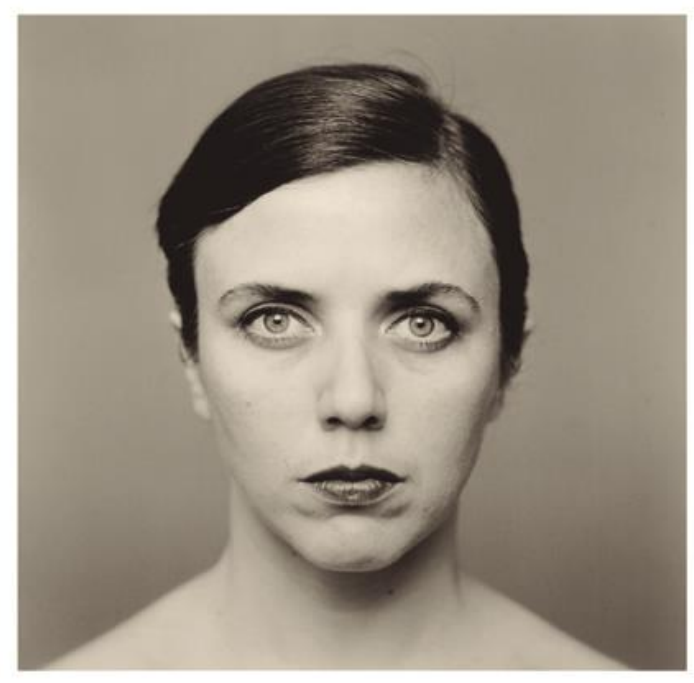

(Fig. 7) María 1978, Humberto Rivas. Archivo Humberto Rivas

Las diversas temáticas de su obra son tratadas por igual, pareciendo ser una misma. El rostro emerge en la escena a través de la mirada, potenciando la expresión y dando significado a la misma, mostrando un diálogo constante entre interior y exterior, exponiendo lo íntimo, lo invisible en la imagen, su psicología. "La gravitación de lo no visto en lo visible se impone a veces con más insistencia que el peso inerte de la crasa materialidad de las cosas" (Schnaith, 2011). Los ojos son el umbral entre lo visible y lo invisible, dan a entender sutilmente mediante un catálogo instintivo de movimientos las emociones interiores. "Transcienden más allá de la mera apariencia, el signo mágico del ojo ha estado omnipresente en todas las culturas y estilos artísticos como símbolo de lo más sobrenatural de la figura humana, ejerciendo una sugestión poderosa sobre quien lo 
contempla fijamente, La certeza de esa revelación es lo que nos sigue atrayendo de la mirada" (Pajares, 1993: $3)$.

Destacar en su obra la representación del paso del tiempo en una doble interpretación. Por un lado, se percibe en un mismo rostro, con las consecuentes huellas del tiempo real; y por otro, cómo el mismo paso de tiempo en su trayectoria profesional va cambiando las características representativas de su fotografía hasta llegar a su serie "Huellas" donde se hace evidente su evolución hacia lo oscuro y la expresividad de la luz sigue siendo protagonista (Fig. 8).

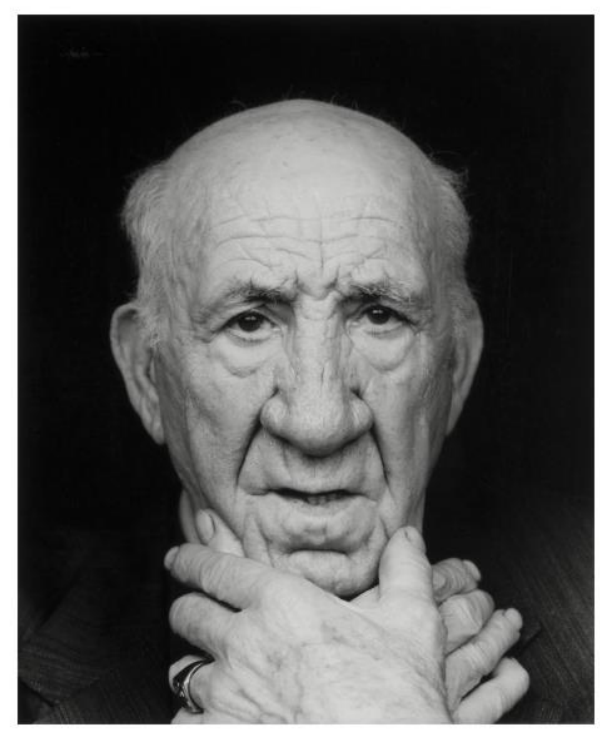

(Fig. 8 ) Toni, 2000. Archivo Humberto Rivas.

Según Jacques Aumont, "El rostro humano, (...) es la parte noble del individuo; principalmente es el lugar de la mirada. Lugar desde donde se ve y desde donde se es visto a la vez, razón por la que es el lugar privilegiado de las funciones sociales, pero también soporte visible de la función más ontológica: el rostro es el hombre" (Aumont, 1992: 17-18). Como decía Roman Gubern El rostro humano es el lugar a la vez más íntimo y más exterior de un sujeto, el que traduce más directamente y de modo más complejo su interioridad psicológica y también el que padece más coerciones publicas (...) El rostro es, a la vez, la sede de la revelación y de la simulación, de la indiscreción y de la ocultación, de la espontaneidad y del engaño (Gubern, 2004:96). El rostro es, en definitiva, nuestro mayor signo de identidad y un verdadero palimpsesto orgánico, pues su movilidad hace que, más que expresiones, resulte pertinente considerar sus resultados como verdaderas "frases faciales" (Gubern 2004:97). En consecuencia, el rostro, como lugar privilegiado de las funciones sociales permite interactuar con el otro cuerpo aportarle información y transmitiendo al espectador esos sentimientos y sensaciones. En la obra de Humberto Rivas el rostro trasmite el paso del tiempo, una vida vivida, desde la piel de la arruga o la perdida de firmeza, y desde la mirada se percibe un estado de melancolía, historia y emoción contenida. Todas estas características están igualmente contenidas en sus paisajes, o naturalezas muertas. Desde una ventana tapiada en una fachada (Fig. 9), dónde perfectamente está reflejado un rostro al que no se puede 
acceder; a una flor marchita donde la textura y caída de su pétalo evidencia una vida vivida y el paso del tiempo. La memoria está escrita en sus rostros, el silencio y la luz de sus calles o cementerios.

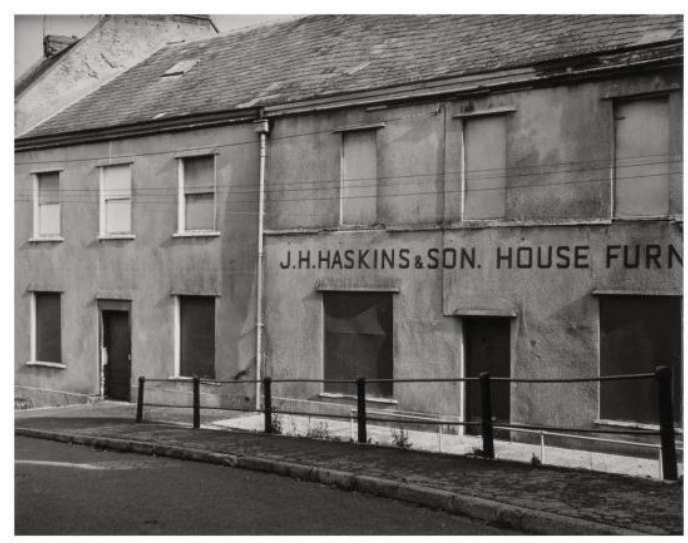

(Fig. 9) Inglaterra, 1979. Archivo Humberto Rivas

El cuerpo es protagonista evidenciando el paso del tiempo y potenciando con diversas partes el significado (Fig. 10). Los brazos, cualquier imagen en la que aparezca un brazo amplio su significado ya que permiten a las manos tocar todas las superficies del cuerpo, son expresivos por su propia naturaleza. Las manos controlan la energía, son objeto de fascinación junto la boca y los labios, las manos tienen más inervación que el resto del cuerpo, expresan un significado que penetra en las barreras de la persona. Es destacable el papel que juega la piel, lejos de su superficialidad es profunda y rica, una barrera sensible y táctil entre dos personas, y entre el interior y el exterior del individuo; es una fuente extraordinariamente poderosa de estimulación sensorial. En ella reside el sentido del tacto; nos permite percibir la presión, la temperatura y el dolor, las fotografías nos dejan intuir la emoción del momento y el recuerdo. La piel es también un lienzo en el que se representa minuciosos detalles simbólicos de la posición social y de la identidad.

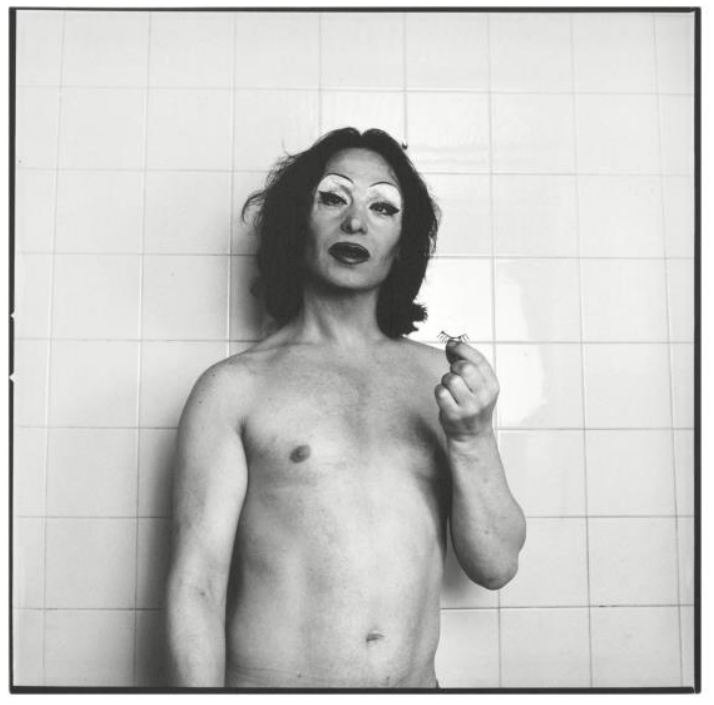

(Fig. 10) Violeta la Burra, 1978. Archivo Humberto Rivas. 
Concluyendo, la situación político-social de un país condiciona directamente el contexto cultural, y una de las funciones de la fotografía es registrar el momento. La aportación de Humberto Rivas a la fotografía española, en este sentido, es reflejar su más íntimo yo, empapado de la situación y el ahora, a través de las múltiples variantes de sus obras. Su fotografía, por tanto, manifiesta la expresión artística, característica principal de la fotografía de los años 70 .

El paso del tiempo está presente tanto en su evolución, en la transformación de las características formales de su obra; como en la misma imagen, en mirada individual. Destacamos la importancia del conocimiento de los recursos materiales y del dominio del medio para transmitir la verdadera intención personal, así como, las relaciones profesionales y personales entre creadores como vehículo transmisor de conocimiento. Dejando una línea de investigación abierta a los conceptos tratados, concluimos que el espacio -tanto físico, como metafísico juega un papel fundamental en este entramado juego de percepciones y se utiliza inconscientemente como nexo de unión, como ágora donde y mediante el cual la representación, visible e invisible se unen.

\section{Referencias}

AUMONT, J. (1997) El Rostro En El Cine. Paidos Iberica Ediciones SA.

COLOMINA, B. (2010). Privacidad y publicidad. La arquitectura moderna como medio de comunicación de masas. Cendeac.

ALBERICH, Jordi (2000). El canto de las sirenas. Ecos posmodernos en la fotografía contemporánea española. $1^{\circ}$ edición, Fundación Espais d'Art Contemporani. Girona.

FONTCUBERTA, Joan (2008). Historias de la fotografía española: escritos 1977-2004. Editorial: Gustavo Gili. ISBN: 9788425222870

FONTANA, Josep (2011). Por el bien del impero una historia del mundo desde. Pasado \& presente. Barcelona.

LONDOÑO PALACIO, O. L. (2006). El lugar y el no-lugar para la muerte y su duelo. Ed. Bogotá, Universidad de Colombia.

LÓPEZ MONDÉJAR, Publio (1977). Historia de la fotografía en España. $4^{\circ}$ edición, Editores Lunwerg.

MARÍ, B.; ZELICH, C.; RIBALTA, J (2012). Centre Internacional de Fotografía Barcelona (1978-1983). MACBA.

SOUGEZ, Marie-Loup (Coord.) (2007); garcía Felguera, M․ De los santos; Pérez Gallardo, helena; Vega, Carmelo (2007). Historia general de la fotografia. Manual de cátedra. Ediciones Cátedra (grupo Anaya, S. A.). Pajares Gómez. J. L. Los ojos. (1994). Universidad Complutense de Madrid.

SCHNAITH, N. (1991) El Cuerpo: Un Codificador Del Alma. Debate Feminista, vol. 2, pp. 155-159.

SCHNAITH, N. QUERALT DOMÉNECH, J. Humberto Rivas. Centro Editor de América Latina. 99. Pp.1-16.

SCHNAITH, Nelly. (2011). Lo visible y lo invisible en la imagen fotográfica. La oficina.

SOTANG, Susang. (2004). Sobre la fotografía. Editora Companhia das Letras.

VÁZQUEZ COUTO, D. (2016) Apariencias de la variación: fisonomía y alegoría en el retrato cinematográfico de Ingmar Bergman . Revista Fotocinema, (12), pp. 131-154

WILLIAM A. E. (2008). El rostro humano. El nuevo retrato fotográfico. Editorial Blume. Barcelona

https://www.macba.cat/uploads/publicacions/cifb/galeria-spectrum_cas.pdf (Consultado: 26-09-2017)

Entrevista personal realizada a Cristina Zelich sobre Humberto Rivas.

Entrevista realizada por Carmen de la Guerra y Javier Díez, La Mirada en el otro. Conexiones-confrontaciones. 
Entrevista realizada por Manolo Laguillo a Humberto Rivas. Archivo Humberto Rivas.

Entrevista realizada por Joan Fontcuberta a Humberto Rivas. Revista Nueva Lente. 